\title{
Y LAS EXPRESIONES DEL PERIODISMO TRANSFORMADO
}

\author{
Por \\ Kevin Alexis García ${ }^{1}$ \\ Docente de la Escuela de Comunicación Social \\ Universidad del Valle \\ kevingar@univalle.edu.co
}

\section{Resumen:}

A menos de una década marcada por los discursos que pronosticaban el fin del periodismo, un vigoroso movimiento ha sacudido los secretos de importantes poderes gubernamentales. No obstante, Wikileaks es sólo la expresión más visible de una serie de transformaciones que viene viviendo el periodismo propiciadas por la Revolución tecnológica. ¿Cuáles son las expresiones de esa transformación y cómo impactan el ejercicio del poder?

\section{Palabras claves:}

Democracia, libertad de expresión, ciudadanía, periodismo, nuevas tecnologías.

\footnotetext{
${ }^{1}$ Comunicador Social, Magister en Literaturas Colombiana y Latinoamericana.
} 
De manera acertada Ramonet entendió que la revolución tecnológica transformaría la definición misma de información que era enseñada en las escuelas de periodismo, aunque reducía dicha transformación a una prevalencia por la inmediatez: "En la actualidad, informar es esencialmente hacer asistir a un acontecimiento, es decir, mostrarlo, situarse a un nivel en el que el objetivo consiste en decir que la mejor manera de informarse equivale a informarse directamente". Consideró que esa característica ponía en cuestión al propio periodismo, por lo menos al paradigma desde el cual él interpretaba.

Dicha inmediatez acentuaba el peligro de desaparición del periodista en la medida que la revolución tecnológica terminara imponiendo un criterio de autoinformación en los ciudadanos. Ante ello señalaba Ramonet que ver no es lo mismo que comprender, los nuevos medios terminarían subsumidos por las agendas de un medio dominante, el cual consideraba era la televisión y temía que un ciudadano no tuviese más criterios de apreciación que comparar informaciones. Sin otros criterios, una posible confabulación de los propios medios acabaría decidiendo qué acontecimientos deberían considerarse como verdaderos.

Por su parte, Bill Kovach y Tom Rosenstiel sostenían que debido a la globalización y el comercio electrónico, las nuevas tecnologías, se convertirían en una de las fuerzas principales que causarían el alejamiento progresivo del periodismo de aquella posición en que éste contribuía a los principios fundamentales de la ciudadanía, "internet ha comenzado a disociar periodismo y fronteras geográficas y por tanto a alejarlo de la comunidad tal y como la conocemos en un sentido político o cívico" (2004:43).

No obstante, en su ensayo apocalíptico Ramonet había reconocido una crisis de inteligibilidad para comprender con precisión su momento: "Sabemos que las cosas han cambiado, disponemos de instrumentos intelectuales, pero estos instrumentos intelectuales y conceptuales no nos permiten comprender la nueva situación. Servían para desmenuzar, analizar y pormenorizar la situación anterior, pero ya no nos sirven para comprender la nueva realidad" (2002).

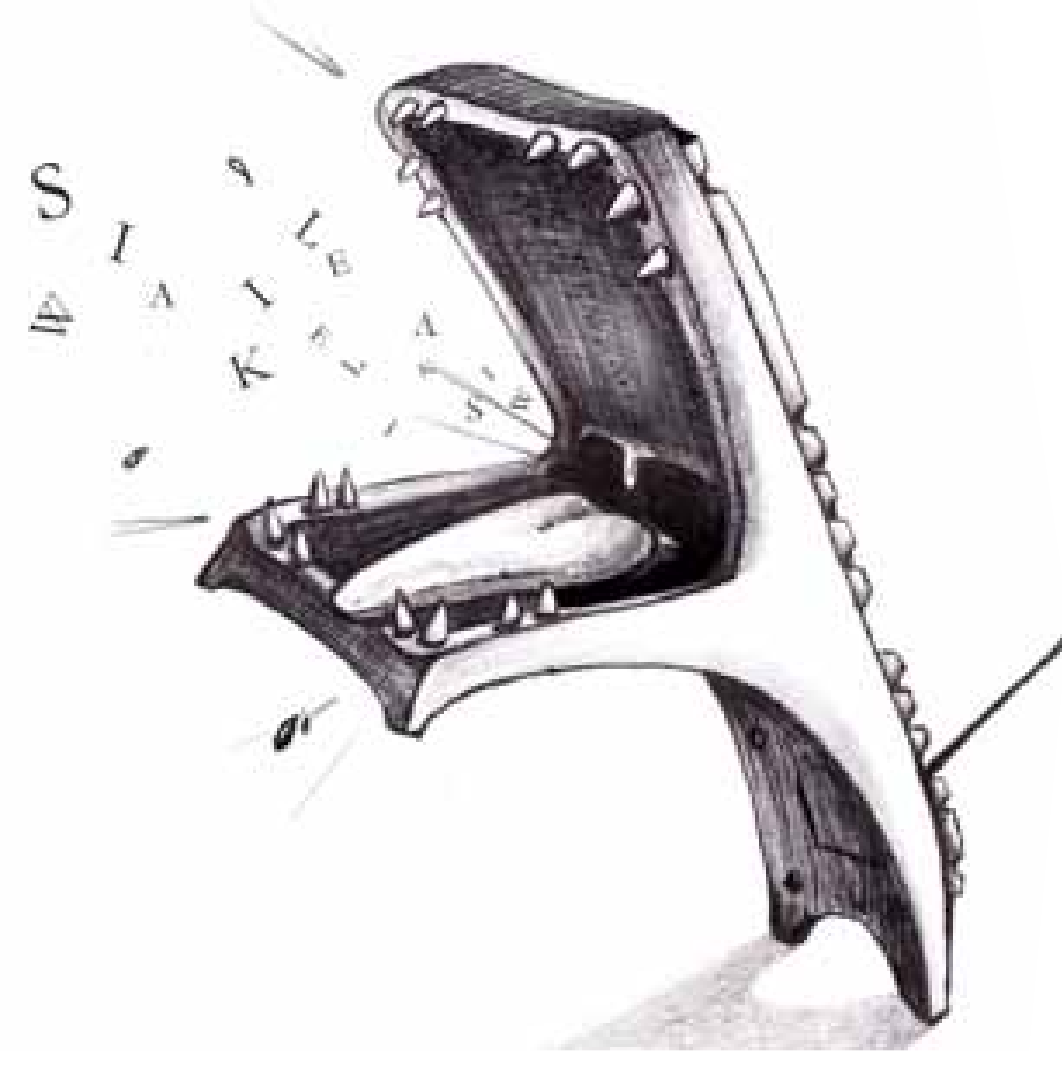




\section{El nuevo escenario del periodismo}

Una expresión de esa nueva realidad no prevista se manifestó el 1 de diciembre de 2010, día en el cual, como parte de su política de censura informática, el gobierno de la República Popular de China bloqueó para sus ciudadanos, los enlaces de acceso al portalWikileaks. Lo hizo para evitar revelaciones de correspondencia diplomática norteamericana que pudiera afectar a Corea del Norte, una de sus naciones aliadas. Wikileaks , una página de internet creada cinco años atrás, sin una sede física definida y entendida por su fundador Julián Assange como una "agencia de inteligencia de la gente”, había publicado tres días antes su tercera ola de grandes revelaciones; a los archivos secretos sobre las guerras de Irak y Afganistán, se sumaban los cables de los servicios diplomáticos de los Estados Unidos alrededor del mundo.

¿Era previsible la reacción del gobierno chino? Éste, dirigido por un régimen unipartidista, se había caracterizado por restringir el acceso a la información y la libertad de expresión; pero su censura sería sólo la punta de un iceberg de persecuciones contra una iniciativa periodística que aprovechaba las nuevas tecnologías. Una notificación también roja, como la bandera comunista, emitía la Interpol con una orden internacional para detener a Julián Assange. Lo acusaban de cometer delitos sexuales en Suecia. La organización que dirigía había filtrado más de 250.000 cables diplomáticos a los diarios The New York Times, The Guardian, Le Monde, El País y el semanario alemán Der Spiegel. Estos medios, todos de gran influencia en sus respectivos países, pudieron producir información exclusiva con contenidos privilegiados de primer nivel. A su vez Assange garantizó que su trabajo llegara, de manera simultánea, a las agendas informativas de Estados Unidos, Reino Unido, Francia, España y Alemania, con lo cual alcanzaría gran resonancia en Occidente, tal como finalmente sucedió.

A menos de una década marcada por los discursos que pronosticaban el fin del periodismo, un vigoroso movimiento ha sacudido los secretos de los principales poderes gubernamentales. La posibilidad que propició la revolución tecnológica de intercambiar contenidos de manera virtual sin restricciones horarias o geográficas, fue aprovechada por Assange para crear una red de colaboradores anónimos, filtradores de información susceptible de representar violaciones a los contratos colectivos de las sociedades, como los derechos humanos, la trasparencia en el ejercicio del poder y el respeto por la sociedad civil en escenarios de guerra. 
En su actual dirección en internet ${ }^{1}$ Wikileaks se ha definido como una organización mediática sin ánimo de lucro, dedicada a ofrecer noticias e información al público. Su trabajo se ha convertido en la expresión más visible de una serie de movimientos gestados en internet por ciudadanos anónimos con propósitos similares. La organización de Assange afirma que publica material de significado ético, político e histórico, manteniendo la identidad anónima de sus fuentes y buscando con esto suprimir las injusticias y censuras. Sostiene que se interesa por denunciar regímenes totalitarios, religiones y compañías alrededor del mundo. Assange canalizó el deseo de denuncia de cientos de ciudadanos. Al poco tiempo de creado, Wikileaks ya filtraba documentos que evidenciaban asesinatos de población inocente por parte de la policía keniata, manuales de tortura y manipulación psicológica de presos, asesinato de civiles en Iraq por parte del ejército norteamericano, así como desfalcos y jugadas ilícitas de grandes corporaciones bancarias. ¿No era esta la utopía de la vigilancia al poder?

Kovach y Rosenstiel recuerdan que hasta 1720, fecha en que algunos periodistas ingleses formularon por primera vez una teoría sobre las libertades de prensa y expresión y argumentaron el derecho a decir la verdad, "el derecho consuetudinario inglés dictaba lo contrario: criticar al Gobierno no sólo era un crimen, sino que cuanto 'mayor verdad (contuviera la crítica), mayor delito'...la verdad, naturalmente, era más dañina” (2004:30). A la par con la información al ciudadano, la vigilancia al poder ha sido un principio constitutivo del oficio periodístico, según Kovach y Rosenstiel (2004:155) desde 1643, cuando surgieron en los cafés de Inglaterra los primeros periódicos impresos, se promovieron las primeras iniciativas de investigación y éstas sustentaron la necesidad de garantizar la libertad de prensa. Umberto Eco ha entendido las revelaciones de Wikileaks como el momento en que las relaciones de control han dejado de ser unidireccionales para volverse circulares. Es la inversión del Gran Hermano, aquella metáfora de George Orwell que concebía al ciudadano convertido en víctima total del ojo del poder. Ahora explica: "El poder controla a cada ciudadano, pero cada ciudadano, o al menos el hacker, puede conocer todos los secretos del poder" (2010).

A pesar de que las instituciones y personas cuestionadas por las filtraciones no negaban la veracidad de los documentos, Assange y sus colaboradores pasaron de recibir el Premio Amnistía Internacional por parte de los medios británicos, en junio de 2009, a ser perseguidos hacia finales de 2010. En ese lapso Wikileaks pasó de filtrar información que comprometía a gobernantes de África y Medio Oriente, a divulgar documentos que evidenciaban los abusos del gobierno norteamericano. Luego de difundir los cables del servicio diplomático, en los cuales la Secretaria de Estado Hillary Clinton aparecía comprometida en órdenes para espiar al secretario 
de general de la ONU, Ban Ki-moon, una serie de persecuciones se desencadenaron contra Wikileaks. ¿Esperaba el gobierno de los Estados Unidos que una pequeña organización de activistas socavara de esa manera su diplomacia en el mundo? De inmediato la entidad financiera suiza PostFinance anunció el cierre de la cuenta abierta por Julián Assange para recibir donaciones. Amazon.com retiró el hospedaje a la página, el sistema de pagos online Paypal suspendió las cuentas de la organización, MarterCard y Visa suspendieron también sus pagos y Julián Assange fue detenido en el Reino Unido.

Wikileaks ha tocado nervios sensibles del oficio periodístico, del contrato social en que soporta la democracia y del ejercicio del poder público. Pero, ¿cómo debemos entenderlo?, ¿representa un nuevo modelo de periodismo?, y si no lo es ¿en qué posición se sitúa respecto al oficio? ¿Es un medio de comunicación o un simple intermediario de información? Esta última pregunta formula Doménico Chiappe (2011) y se responde:

"De ser lo primero los medios tradicionales habrían fallado al no haber contrastado las fuentes. En los cables diplomáticos y en otras informaciones de Wikileaks no ha mediado la edición y, al no existir esta intermediación periodística, podría creerse que Wikileaks no es un medio de comunicación. Pero sí lo es por un factor clave: tiene una agenda, centrada en la divulgación de aquello que afecte y desacredite a Estados Unidos... (2011)”2.

Centrémonos especialmente en la afirmación de que wikileaks es un medio de comunicación por tener una agenda, en palabras del autor destinada a afectar a Estados Unidos; esto resulta insuficiente y refleja un error de percepción, pues Chiappe estaría reduciendo todas las actividades de esta organización a las filtraciones del año anterior, donde los cuestionamientos a la diplomacia norteamericana alcanzaron alta figuración mediática (ver cronología de Wikileaks al final del documento). Con la revolución tecnológica asistimos a una transformación del periodismo, de la cual wikileaks es su expresión de mayor impacto. En una entrevista para la revista Semana, a Assange se le interroga por una definición de su organización:

SEMANA: ¿Clasificaría a WikiLeaks como un alborotador del establecimiento, como un activista del derecho a estar informado, como una superfuente de información en la nueva era digital o como una forma de hacer periodismo?

J.A.: Es todo eso. Estamos planteando nuevos estándares. ¿Para qué es el periodismo? No es solo para que los dueños de los medios tengan ganancias, debe buscar un servicio público. No es solo para producir ganancias...WikiLeaks no es una organización convencional. Trabajamos por el derecho que tiene la gente a saber y a publicar.

(http: / / www.semana.com/nacion/colombia-muy-interesante-para-wikileaks/153606-3.aspx) 
La respuesta de Assange denota una de las preocupaciones que formulaba Ramonet, la subordinación cada vez más creciente del periodismo a las expansivas lógicas del mercado, en detrimento de la independencia y la libertad de información. En el mismo sentido se expresaban Kovach y Rosenstiel: "la fusión de empresas periodísticas amenaza la supervivencia de la prensa como institución independiente a medida que el periodismo se convierte en una actividad subsidiaria de las grandes corporaciones que basan su gestión en otros objetivos". (2004:45) Frente a esto, en la respuesta de Assange se manifiesta una profunda inflexión del periodismo que en su momento Ramonet no alcanzó a prever. La revolución tecnológica ha propiciado la emergencia de iniciativas hibridas que, gracias a la masificación de los medios de producción y comunicación, y a los desarrollos de tecnologías como internet 2.0 han transformado la relación entre productores y consumidores de la información.

Ramonet señaló los peligros del monopolio de los medios informativos, pero no pensó las posibles respuestas ciudadanas. En medio de la crisis del modelo económico convencional de la prensa escrita, y en un entorno cada vez más controlado por entornos virtuales, la masificación de los medios de producción ha permitido que el capital no sea una herramienta de distinción tan decisiva como en el mundo físico. $\mathrm{Si}$ bien las grandes industrias informativas han migrado a internet y disponen sus recursos para desarrollar poderosas plataformas virtuales, también se han venido consolidando experiencias alternativas de información. Las transformaciones del periodismo, expresadas de manera notoria por la coyuntura de wikileaks, hoy ocupan un espacio central en las agendas públicas. En medio de las progresivas mutaciones de la industria de la información, ha aumentado la conformación de salas de prensa independientes y especializadas (del tipo www.propublica.org y www.razonpublica. com), que aprovechan los menores costos de la publicación online para congregar recurso humano calificado y ejercer el periodismo, con fuentes de financiación alternativas y menores expectativas de lucro. Por otra parte, las posibilidades tecnológicas propiciadas por internet 2.0, especialmente para suprimir la división entre productores y consumidores de información, ha estimulado el surgimiento de un periodismo empírico (del tipo www.soyperiodista.com), no especializado, que hoy reclama la atención de los profesionales de la comunicación. Una definición que expresa esta nueva hibridez es prosumidor, y alude a una generación de ciudadanos con capacidad instalada para consumir y a su vez producir información desde entornos cotidianos.

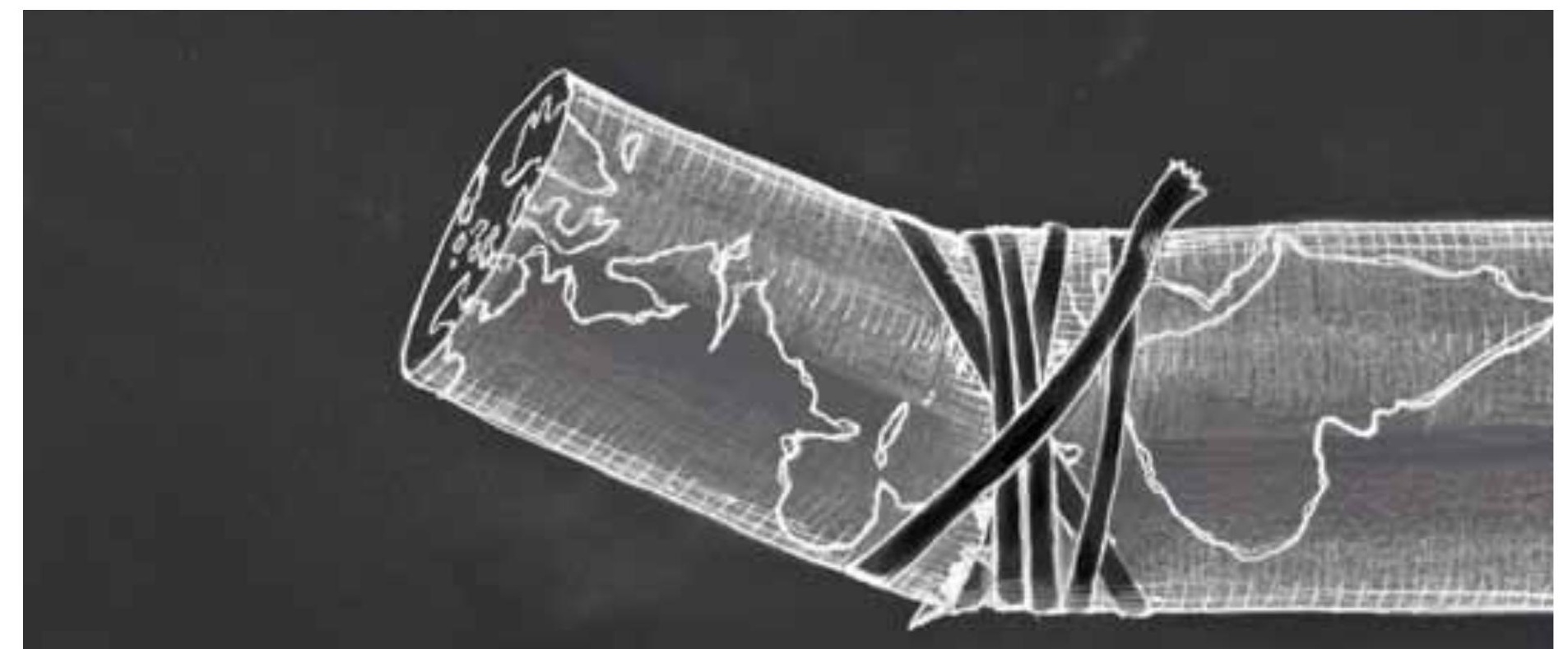




\section{Las transformaciones del oficio}

En un artículo publicado en la revista Harvard acerca de las nuevas voces del periodismo en América, Juanita León expone ocho características de la transformación que viene presentando el periodismo en las nuevas tecnologías. Por lo menos los cambios que ella y su equipo de colaboradores han venido experimentando en lasillavacia.com, un medio pensado para indagar las estructuras del poder en Colombia, creado en 2009, que se ha convertido en el cuarto medio más consultado por los columnistas de opinión del país.

Dicha transformación del oficio en internet incluiría cambios en la forma de concebir las noticias, las fuentes, la relación con el público, así como los sistemas de producción de la información. Como primer elemento señala León que en internet la información cruda es la historia. Si bien en la prensa escrita, televisiva o radial, los medios informativos están supeditados a un espacio físico y temporal que delimita y determina la extensión y el volumen de la información, en internet está limitación es superada. De tal forma que medios como La silla vacía han podido diversificar el concepto del contenido publicable.

Una pieza periodística convencional era entendida como una obra procesada, como la síntesis de un trabajo de reportería por parte de un periodista que podía recurrir a lectura de documentos, inspección de escenarios, realización de entrevistas y en algunos casos a análisis de la información, hasta obtener los insumos necesarios que le permitieran decantar una nota compuesta bajo las claves de un género. Pero paralelo con este proceso de producción, gracias a la capacidad de almacenamiento de información en línea y a las tecnologías virtuales de interacción, la información cruda, en otro tiempo considerada insumo, ahora también es publicada. Una expresión de este cambio el aprovechamiento que hizo wikileaks para divulgar más de 250.000 cables norteamericanos.

La posibilidad de los ciudadanos para acceder a un medio virtual sin restricciones horarias o geográficas, ha permitido que la relación entre productores $\mathrm{y}$ consumidores de información a su vez se transforme. Los usuarios pueden conocer los insumos de trabajo del periodista (correos filtrados, actas notariales, proyectos de ley, testimonios, interceptaciones telefónicas) y formular sus propias interpretaciones. Bajo esta premisa León sostiene que en su medio virtual permiten que los documentos hablen por sí mismos. Como ejemplo de ello otorgan claves de acceso a personalidades de la política nacional para que publiquen sus opiniones sobre temas de la agenda del momento, sin que sean subsumidas en otro texto. 
Una expresión más compleja de este concepto son las bases de datos virtuales, como el proyecto Políticos do Brasil, sus realizadores sistematizan y publican de los políticos datos personales de interés público, información electoral, votos alcanzados y declaraciones de bienes que presentan ante la justicia electoral. Esta información cruda es útil a múltiples propósitos. Un ciudadano puede conocer el número total de votos que alcanzó su candidato en las últimas elecciones, a la vez que un periodista puede rastrear incrementos patrimoniales desmesurados, así como el inventario de bienes y los ingresos de cada candidato.

Una segunda característica radica en que El contexto es la historia. Señala León que en medio del caudal de informaciones y la masificación de los medios de producción, el contexto deja de ser el trasfondo de la noticia para convertirse en la propia noticia. Ramonet señalaba como durante mucho tiempo se consideró que entre mayor fuera la información mayor sería la libertad de los ciudadanos. Sin embargo, sostenía que llegado un período de superabundancia surgía la necesidad de reconocer aspectos cualitativos en el momento de seleccionar la información: "por muy abundante que sea la información, la que más me interesa es la que es creíble y fiable y, por tanto, la que tiene un mínimo de garantías relacionadas con la ética, la honestidad, la deontología o la moral". Frente a la sobreexposición de información que propició la revolución tecnológica, el acopio y selección adquiere valor de consulta por parte de los lectores.

Como una tercera característica, más relacionada con la primera, Juanita León indica que en internet El proceso de hacer la historia es también la historia: "Publicamos todos los documentos que hemos utilizado, las notas que tomamos... cada pieza en bruto de la información que nos ayudó a construir la historia. De esta manera, los usuarios pueden leer la historia en dos niveles, evaluar nuestras conclusiones con la reportería en que se basó, y también utilizar los documentos para sus propios fines. Esto nos da más credibilidad”.

La cuarta manera distinta en que León piensa el periodismo estaría ligada a la consideración de que La noticia es una historia colectiva. Durante mucho tiempo autores como James Carey han sostenido que el periodismo se justificaba a sí mismo en nombre del ciudadano, pero que en éste el ciudadano no desempeñaba un papel mayor al de audiencia. Por su parte, Lippman, consideraba a los ciudadanos como espectadores de teatro que "llegan hacia la mitad del tercer acto y se marchan antes de que caiga el telón, quedándose el tiempo suficiente para decidir tan sólo quién es el héroe y quién el villano de la función” (Kovach y Rosenstiel, 2004:36). En internet, cada vez es mayor el número de medios virtuales que conciben a sus lectores como potenciales colaboradores de sus actividades, desde divulgadores de las noticias a través de sus perfiles en las redes sociales, hasta usuarios generadores de información útil. Medios como La silla vacía, crean sus propios perfiles en redes como Facebook, y desde allí pueden escuchar opiniones y conocer pistas para desarrollar información. Los usuarios a su vez pueden verificar hechos, proponer conexiones con fuentes no consideradas por el medio, suministrar insumos para ayudar a avanzar investigaciones y formular propuestas para próximos temas. 
La quinta consideración que propone León se relaciona con la necesidad de cubrir en El tiempo real de la historia. Esta prevalencia por la inmediatez en el cubrimiento implementada primero por los noticieros de televisión, ya ha sido cuestionada por autores como Ryszard Kapuscinski, el cual señalaba que "Estamos sobreexpuestos a los medios pero faltos de información. Debemos comprender que ver no es lo mismo que entender, la información se hace ligera y no perdura. Lo urgente se confunde con lo importante ${ }^{\prime \prime}$. Con la progresiva incorporación de las tecnologías para la transmisión en vivo, a los medios se les criticó que, en el afán por generar primicias, en un ambiente de competencia por informar primero, terminaran replicando notas urgentes, descontextualizadas, carentes de interpretación y análisis. Sin embargo, en internet la obsesión por la simultaneidad adquiere otro matiz. Tal como lo anuncia León, el interés se centra en satisfacer el deseo del lector por asistir a la generación de la noticia, por vivir el acontecimiento y presenciar en tiempo real los sucesos. Los tiempos indefinidos de emisión en internet les permiten a los medios realizar cubrimientos de sesiones legislativas en el Congreso, realizar video chats con los protagonistas de la información y con participación de los lectores. Ejemplo de simultaneidad son los módulos de Twitter que dispusieron en sus primeras pantallas medios como El Tiempo, El País y La silla vacía para informar los pormenores de acontecimientos como el fallo de la Corte Constitucional acerca de la segunda reelección y la liberación de secuestrados.

La anterior característica podría considerarse una antesala de un sexto cambio en las maneras de entender el periodismo en internet; señala León que La noticia es una experiencia de inmersión, "La mitad de nuestra audiencia creció jugando juegos de video. Nuestro objetivo es ofrecerles, en un par de años, la posibilidad de tener una experiencia interactiva en las noticias... ofrecerles la posibilidad de ser los protagonistas virtuales de nuestras historias, para experimentar los dilemas de los responsables políticos y para que puedan "intervenir" con sus decisiones". El aprovechamiento de los recursos de los videojuegos permitiría propiciar una experiencia interactiva, mediante simulación virtual de escenarios y situaciones. En el ámbito del periodismo cultural experiencias cercanas empiezan a vislumbrarse con los recorridos virtuales que ofrecen iniciativas como Art Project de Google, en la cual es posible hacer recorridos a través de escenarios virtuales representados en tercera dimensión de algunos de los principales museos del mundo como El Museo de Arte Moderno de Nueva York, el Reina Sofía de Madrid, el Museo Hermitage de San Petersburgo y el Van Gogh de Ámsterdam. En un futuro sería posible enterarse de la apertura de una exposición en un escenario local y efectuar el recorrido virtual para conocer la obra seleccionada, la dimensión y ubicación de las piezas, así como la información curatorial.

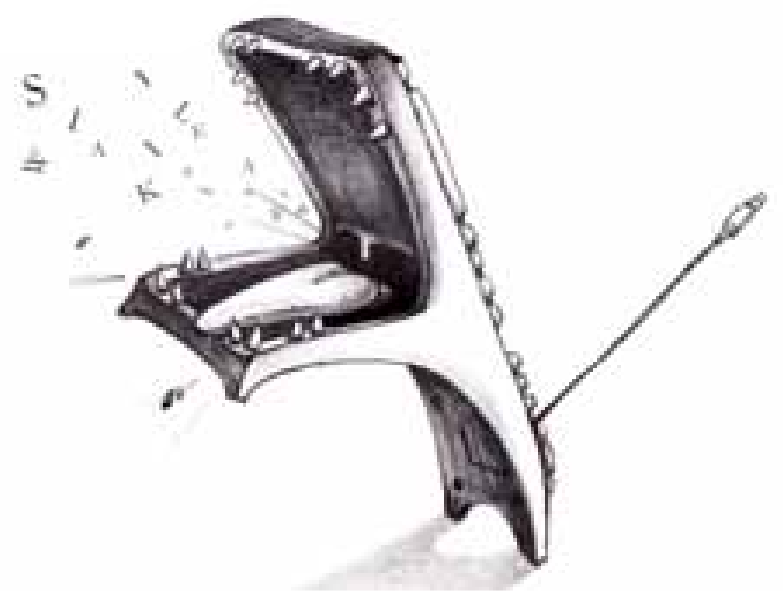


Esta búsqueda de inmersión aproxima una séptima característica señalada por León: Las herramientas son la historia. Con ello destaca la necesidad de que el periodismo explore permanentemente nuevas formas de acceso, interacción y disposición de la información, acordes con el entorno multimedial. Cada vez es más recurrente un escenario de convergencia entre soportes textuales, sonoros, fotográficos y audiovisuales, acompañados de ilustraciones como infografías. Los nuevos medios buscan que en el mismo momento de lectura de una noticia, un ciudadano pueda participar de una encuesta de opinión sobre el tema, conocer la ubicación geográfica del lugar del acontecimiento, mediante herramientas como google maps y participar, posteriormente, de foros de discusión en el propio medio y en las redes sociales. Sostiene León que "la noticia también se produce en la interacción de los usuarios con el resto de la comunidad de usuarios”. Consideración que nos conecta con una octava característica acerca de los cambios que las nuevas tecnologías han propiciado para la generación de las noticias. La historia es la conversación agregada y revisada en la web. Cada vez el ciberespacio se consolida como una poderosa esfera pública que genera múltiples debates. De allí que una nueva rutina periodística sea revisar los comentarios de las redes sociales. Cada vez son más recurrentes las confrontaciones ideológicas entre actores políticos así como la divulgación de noticias de interés público por parte de los tomadores de decisión.

El interrogante que surge es ¿estas transformaciones fortalecerán la democracia?, ¿cómo pudimos pasar de un momento de expectativas apocalípticas sobre el periodismo, a un florecimiento de nuevos medios? Ramonet sostuvo que la revolución tecnológica favorecería una conectividad de globalización y una emancipación del mercado. Pero dicha conectividad cada vez más globalizante ha terminado favoreciendo la construcción de una esfera de discusión sobre los asuntos de interés públicos. Aquellos espacios virtuales poco notables (pequeños blogs de activistas) y las plataformas web gratuitas (facebook, youtube) terminaron propiciando bastas movilizaciones en países como Egipto, Túnez, Yemen, Bahrein, Marruecos, Siria y Libia, naciones controladas durante décadas por dictaduras. Al respecto Boris Salazar señala:

¿Tuvieron las tecnologías virtuales un papel en la oleada revolucionaria del norte de África? Sí: aceleraron los procesos de coordinación de las acciones y permitieron la emergencia de vínculos entre seculares y musulmanes, superando la interferencia de los regímenes dictatoriales de la región. Lo hicieron uniendo y activando núcleos, vínculos, grupos y sentimientos "reales" ya existentes. La combinación entre indignación real y medios virtuales resultó explosiva en una región en la que el honor y la dignidad todavía tienen valor práctico. 
Sin embargo, en momentos de coyuntura Salazar llama la atención sobre la necesidad de reconocer los procesos históricos de resistencia de los propios ciudadanos para evitar fetichizaciones desmesuradas de la revolución tecnológica. Recuerda que Asmaa Mafouz, una de las fundadoras del movimiento Seis de Abril, creado en facebook para apoyar una huelga en el norte de El Cairo, era una activista que venía liderando previamente procesos de movilización. Es en la convergencia de la conectividad virtual y la conectividad real donde los ciudadanos pueden propiciar cambios en el sistema de poder que los gobierna. Recuerda Salazar que "las nuevas tecnologías digitales permitieron la casi instantánea conexión de activistas y ciudadanos, desatando una oleada de protestas que devinieron revoluciones, y aun siguen en proceso de serlo. Conexión antes imposible debido al carácter opresivo de los regímenes despóticos del norte de África”. Las nuevas tecnologías funcionaron como atajo para construir redes y burlar la represión de los gobiernos, evitando así la sangre y el terror, en que terminaban las pequeñas congregaciones, antes de generar grandes procesos de movilización. Durante las protestas en Egipto, el gobierno de Mubarak puso fuera de servicio la telefonía celular y deshabilitó internet esperando que la incomunicación deteriorara las manifestaciones. Sin embargo, en momentos de desconexión la cadena Al-Jazira permaneció en el lugar de las manifestaciones, haciendo aquello que Ramonet tanto temía y que terminaría propiciando resultados inesperados; Al-Jazira permaneció informando en vivo y en directo, haciendo partícipes a millones de televidentes de aquellas manifestaciones.

Mientras Julián Assange afronta su prisión domiciliaria, las persecuciones contra su organización representan un interrogante para la libertad de expresión y la vigilancia al poder, actividades inherentes de la transparencia y el contrato social que da sentido a la democracia. Los actos de wikileaks han alcanzado lo impensable: socavar los sistemas de seguridad de poderosos gobiernos y corporaciones para denunciar la corrupción y los oprobios cometidos de espaldas a la ciudadanía. En las nuevas tecnologías el periodismo se transforma.

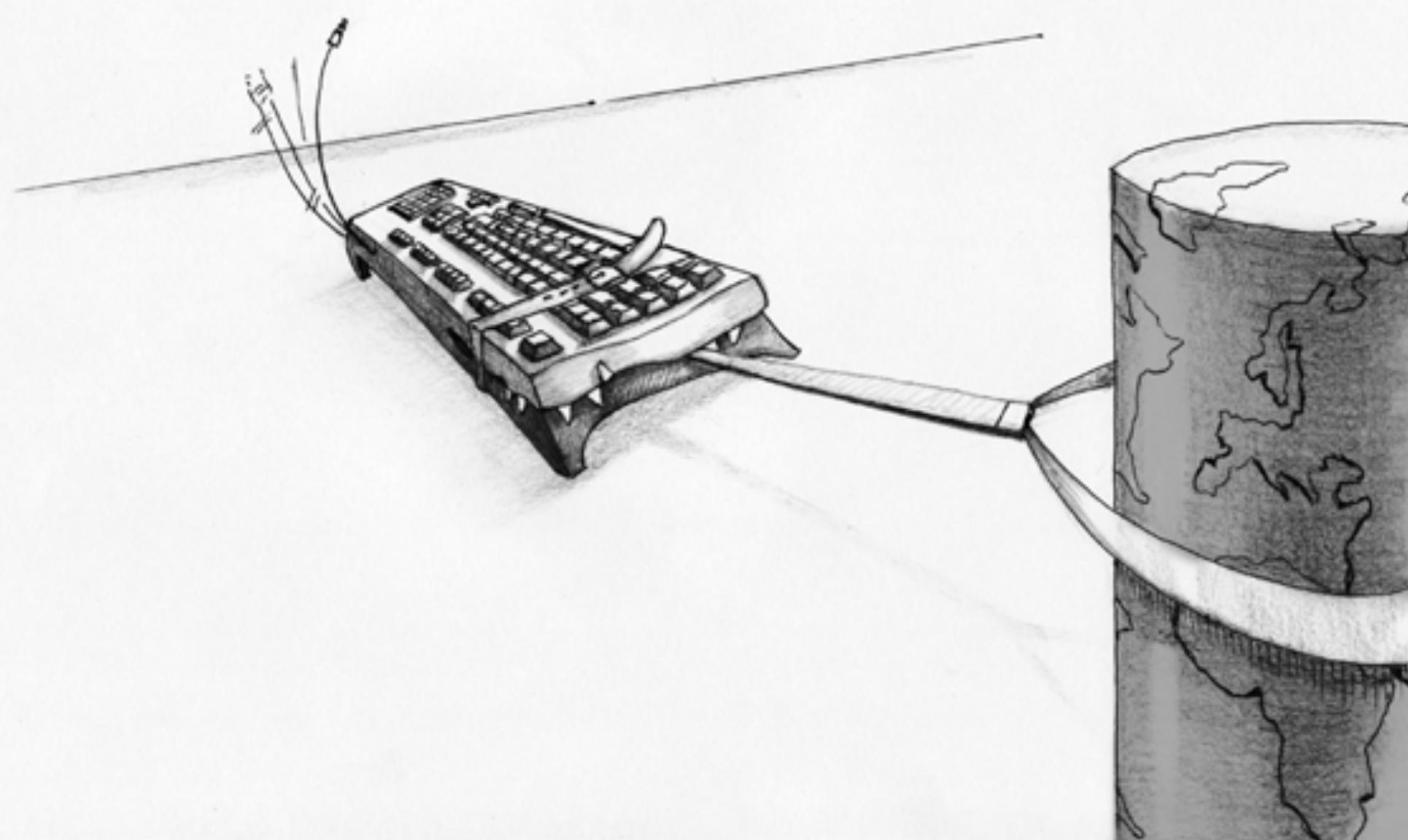




\section{Anexo: Cronología de Wikileaks}

2006

- Octubre 4. Julián Assange registra en internet el domino Wikileaks.org, para filtrar desde allí los abusos del poder en el mundo.

- Diciembre. Es lanzado oficialmente el portal y sus directivos realizan las primeras publicaciones.

2007

- Junio. Wikileaks anuncia que tiene 1.200.000 documentos para su publicación.

- $\quad$ Agosto. El diario The Guardian, gracias a las filtraciones de Wikileaks, publica evidencias de corrupción del presidente de Kenia, Daniel Arap Moi, así como del uso de "patrullas de la muerte” con las cuales la policía de ese país asesinó a población inocente.

- Noviembre. Wikileaks publica el manual del Centro de Detención de Guantánamo. En él se detallan, de manera pormenorizada, el trato que deben recibir los prisioneros, se dictan instrucciones para realizar manipulaciones psicológicas, y se describen prácticas como el uso de perros para la intimidación de los presos.

- Diciembre. Se une a la organización Daniel Domscheit-Berg, principal socio de Assange.

\section{8}

- Enero. Wikileaks difunde documentos sobre la sucursal del banco sueco Julius Bär en las Islas Caimán.

- Febrero. La casa bancaria Julius Bär demanda a Dynadot, la compañía que hospeda el portal de Wikileaks , para que suspenda los servicios; sin embargo, no lo logra y debe retirar la demanda.

- Marzo. Wikileaks publica la Biblia secreta de la Cienciología.

- Junio. Publica los documentos titulados "Memorándum de Entendimiento" que profundiza las denuncias sobre violaciones del gobierno de Kenia.

- Septiembre. La organización difunde emails privados de Sarah Palin, candidata vicepresidencial a los Estados Unidos y pone en evidencia sus posibles violaciones a la ley de transparencia.

- Noviembre. Wikileaks publica una lista de miembros xenófobos de la extrema derecha del Partido Nacional Británico. Divulga nombres, apellidos, direcciones y teléfonos. Publica además el informe de la Oscar Foundation acerca de los asesinatos por encargo de la policía keniata.

- Diciembre. Wikileaks publica documentos del Servicio de Inteligencia Federal (BND) sobre la lucha contra la corrupción en Kosovo y la colaboración con los medios alemanes. Divulga el manual de Human Terrain Team de 2008, un proyecto secreto del Ejército de los Estados Unidos.

- Julián Assange y Daniel Domscheit-Berg dan una conferencia en el Chaos Comunication Congress. 


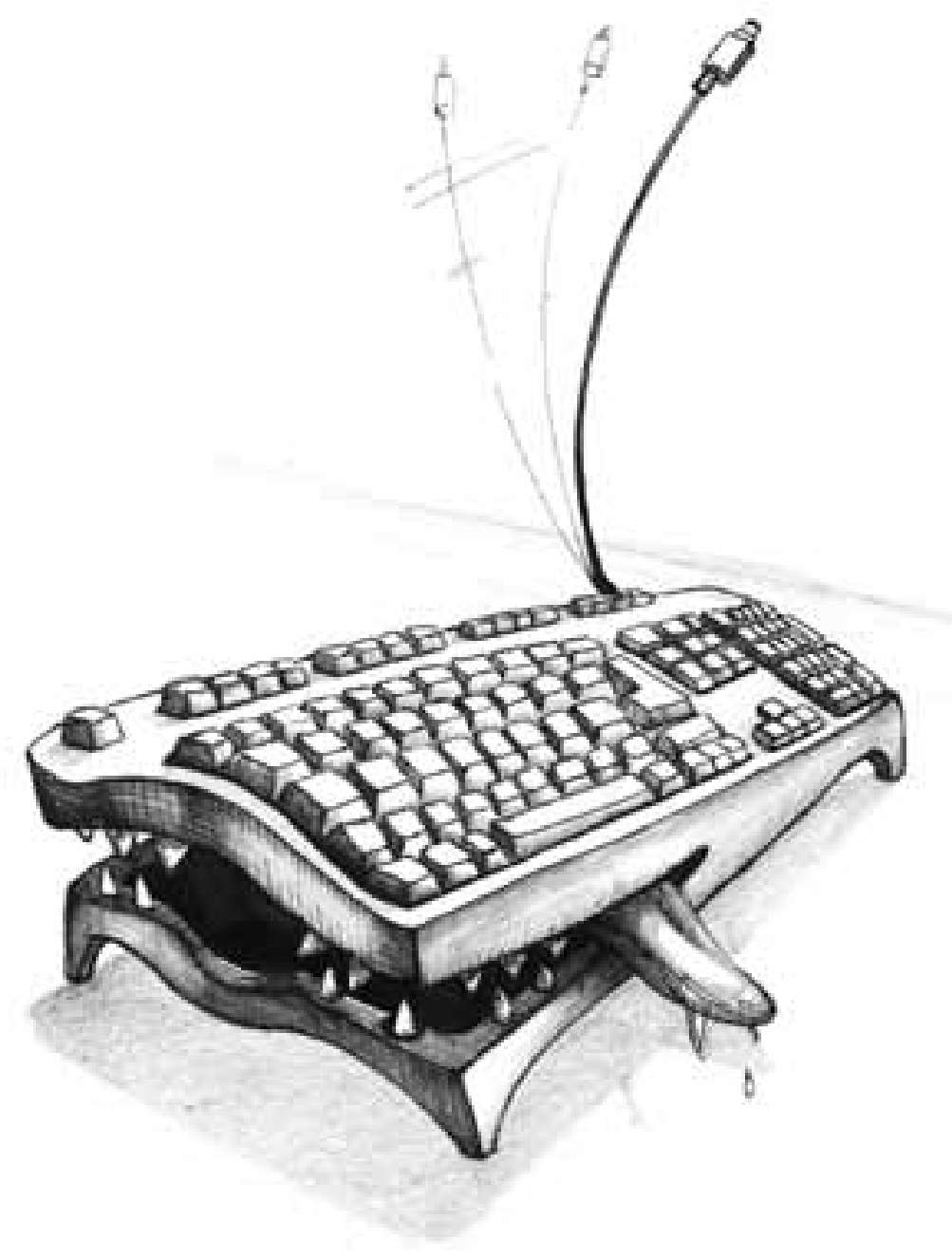

- Febrero. Wikileaks publica 6700 informes del Servicio de Investigación del Congreso.

- Publica las direcciones de los correos electrónicos de sus donantes.

- Marzo. Wikileaks publica la base de datos de los patrocinadores del senador de los Estados Unidos Norm Coleman.

- Abril. La organización participa en el Festival Internacional de Periodismo en Perugia, Italia.

- Junio. Wikileaks recibe el Premio Amnistía Internacional por parte de los medios británicos.

- Julio. Filtra una lista de los mayores deudores del banco Islandés Kaupthing, comprometidos con millonarios desfalcos.

- Agosto. Julián Assange y Daniel Domscheit-Berg asisten a la conferencia de Hacking at Random en Vierhouten, (Países Bajos).

- Septiembre. Wikileaks recibe el premio Ars Electronica en la categoría "Comunidades Digitales"

- Octubre. Publica una segunda lista de miembros del Partido Nacionalsocialista Británico.

- $\quad$ Noviembre. Publica mensajes del buscapersonas del 11-S.

- Divulga el expediente de las diligencias efectuadas contra una empresa farmacéutica alemana.

- Publica los contratos de Toll Collect (peaje para camiones en Alemania).

- Impulsa la idea de un puerto franco de los medios, en la que se basa la Icelandic Modern Media Initiative (IMMI, Iniciativa Islandesa para Medios de Comunicación Modernos).

- Publica los mensajes privados de los correos electrónicos del polémico historiador David Irving, defensor de Hitler.

- Diciembre. Wikileaks difunde el informe Feldjager sobre el bombardeo de dos vehículos cisterna en Kundus, Afganistán.

- Diciembre. 23: es desconectado Wikileaks .

- 27: Daniel Domscheit-Berg y Julián Assange hablan sobre el futuro de Wikileaks en el Congreso Chaos Communication. 
- Enero. La organización comienza a trabajar en Islandia, respaldada por la Iniciativa Islandesa para Medios de Comunicación Modernos (IMMI).

- Abril. Wikileaks publica el video Asesinato colateral. En él se registra cómo un helicóptero norteamericano dispara contra doce civiles, asesinando a un periodista de la Agencia Reuters. La versión oficial del gobierno sostenía que la muerte había obedecido a un accidente.

- Mayo. El soldado norteamericano Bradley Manning es arrestado, acusado de entregar los archivos a la organización de Assange.

- Julio.Wikileaks publica el Diario de guerra de Afganistán. Los archivos revelan que el ejército norteamericano asesinó a civiles, entre ellos a niños, y realizó operaciones encubiertas de las cuales nunca informó públicamente.

- Agosto. 20: Se emite una orden de arresto contra Julián Assange por violación y acoso a dos mujeres que tuvieron relaciones casuales con él, cuando se encontraba en Suecia.

- Octubre. Assange escoge un bunker antinuclear a treinta metros bajo tierra en Estocolmo, para guardar toda la información de la organización; allí se encuentran las oficinas del proveedor de Internet Bahnhof AB. Dentro del bunker hay 8.000 servidores, de los cuales dos son de Wikileaks .

22: Wikileaks publica los Diarios de la guerra de Irak.

- Noviembre. Divulga los cables diplomáticos de los Estados Unidos.

- Diciembre. Interpol emite una notificación roja con Orden de captura internacional para Assange.

- Diciembre. Assange se entrega a la policía Londinense.

- 14: Assange queda en libertad bajo fianza.

2011

- Febrero. La agencia de noticias noruega NTB informa que Wikileaks fue nominado como candidato al Premio Nobel de Paz 2011.

- Marzo. Wikileaks publica el asesinato de nueve españoles en Ruanda.

13: El portavoz del Departamento de Estado de Estados Unidos renuncia luego de que se divulgaran imágenes en las que crítica al Pentágono por las condiciones de detención de Bradley Manning, el soldado acusado de filtrar documentos oficiales a Wikileaks.

(Reconstrucción cronológica con la colaboración Ana María Posada)

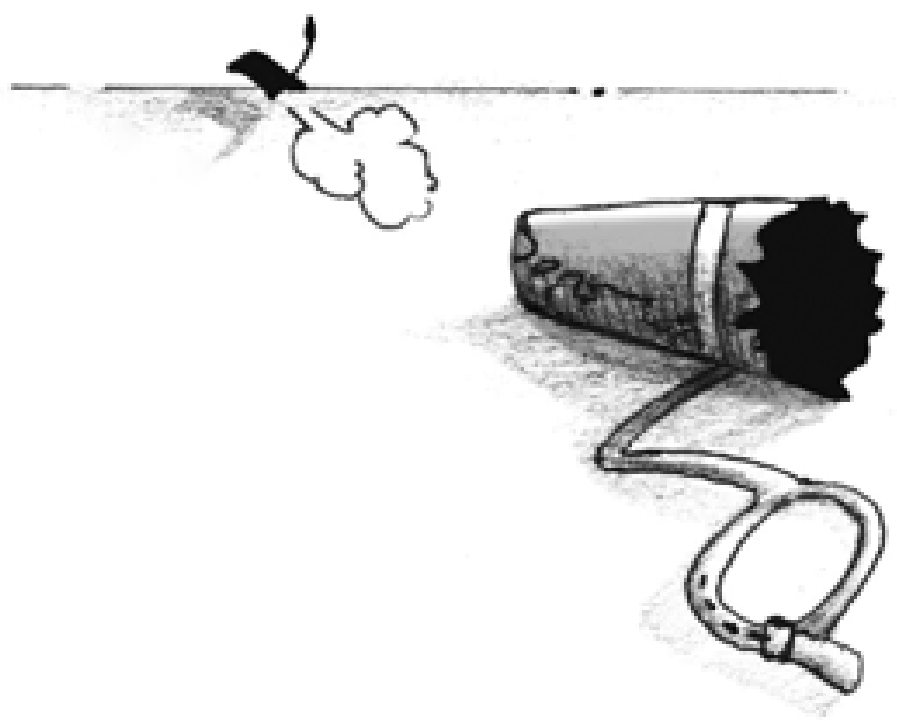




\section{Notas}

\footnotetext{
${ }^{1}$ En la actualidad al portal se puede acceder a través de http://wikileaks.ch/

${ }^{2}$ http: / / www.fronterad.com/?q $=$ wikileaks-y-el-mal-periodismo\&page $=0,0$

${ }^{3}$ http: / / periodismoyliteratura.com/kapu.htm. Recuperado en mayo 30 de 2011
}

\section{Referencias}

- Chiappe, Doménico (2011). WikiLeaks y el mal periodismo. En Frontera D. Recuperado en junio $6 \mathrm{de} \mathrm{http://www.fronterad.com/?q=wikileaks-y-el-mal-periodismo \& page}=0,0$

- Domscheit-Berg, Daniel. (2011). Dentro de WikiLeaks. Mi etapa en la web más peligrosa del mundo. Barcelona: Roca editorial.

- $\quad$ Eco, Umberto (febrero 12 de 2010). Hackers vengeurs et espions en diligence. En Libération. fr. Recuperado en mayo 15 de http://www.liberation.fr/monde/01012305696-hackersvengeurs-et-espions-en-diligence

- García, Kevin. (2007). El periodismo se desviste. Entrevista con Ryszard Kapuscinski. En Periodismo y literatura. Recuperado en mayo 15 de http://periodismoyliteratura.com/kapu. htm

- Gómez A., Juan Gabriel (2011, 25 de enero). Por si no te has dado cuenta (o no has querido hacerlo): la relación entre los diplomáticos, los medios y el público cambió irremediablemente. El Espectador. Recuperado el 30 de mayo de, http:/ /blogs.elespectador. com/cosmopolita/2011/01/25/por-si-no-te-has-dado-cuenta-o-no-has-querido-hacerlola-relacion-entre-los-diplomaticos-los-medios-y-el-publico-cambio-irremediablemente.

- $\quad$ Kovach, Bill y Rosenstiel Tom. (2004). Los elementos del periodismo. Madrid: Ediciones El País.

- León, Juanita (spring-summer 2011). La Silla Vacía. Eight Ways the Internet Changes the Way We Think about the News. En ReVista. Harvard Review of Latin America. Recuperado en mayo 20 de http://www.drclas.harvard.edu/publications/revistaonline/spring-summer-2011/ la-silla-vacía

- Ramonet, Ignacio (2002). Los periodistas están en vías de extinción. En Sala de prensa. Edición 46. Año IV, Vol. 2 Recuperado de http://www.saladeprensa.org/art382.htm, en mayo 15 de 2011.

- Revista Semana (marzo 19 de 2011). "Colombia es muy interesante para WikiLeaks". (Entrevista a Julián Assange). Recuperado en mayo 15 de http: / www.semana.com/nacion/ colombia-muy-interesante-para-wikileaks/153606-3.aspx

- Salazar, Boris (2011, 1 de mayo). Las revoluciones del norte de África: no es la tecnología, es la conectividad. En Razón Pública. Recuperado el 30 de mayo de http://www.razonpublica. $\mathrm{com} /$ index $\cdot$ php?option $=$ com_content $\&$ view $=$ article $\& i d=2003$ :las-revoluciones - del norte-de-africa-no-es-la-tecnologia-es-la-conectividad\&catid $=23$ :internacional\&Itemid $=32$ 